\title{
The game theory of Candida albicans colonization dynamics reveals host status- responsive gene expression
}

\author{
Katarzyna M. Tyc ${ }^{1,4}$, Sanna E. Herwald², Jennifer A. Hogan², Jessica V. Pierce ${ }^{2,5}$, Edda Klipp ${ }^{*}$ \\ and Carol A. Kumamoto ${ }^{2,3^{*}}$ (I)
}

\begin{abstract}
Background: The fungal pathogen Candida albicans colonizes the gastrointestinal (Gl) tract of mammalian hosts as a benign commensal. However, in an immunocompromised host, the fungus is capable of causing life-threatening infection. We previously showed that the major transcription factor Efg1p is differentially expressed in Gl-colonizing C. albicans cells dependent on the host immune status. To understand the mechanisms that underlie this hostdependent differential gene expression, we utilized mathematical modeling to dissect host-pathogen interactions. Specifically, we used principles of evolutionary game theory to study the mechanism that governs dynamics of EFG1 expression during C. albicans colonization.
\end{abstract}

Results: Mathematical modeling predicted that down-regulation of EFG1 expression within individual fungal cells occurred at different average rates in different hosts. Rather than using relatively transient signaling pathways to adapt to a new environment, we demonstrate that C. albicans overcomes the host defense strategy by modulating the activity of diverse fungal histone modifying enzymes that control EFG1 expression.

Conclusion: Based on our modeling and experimental results we conclude that $C$. albicans cells sense the local environment of the Gl tract and respond to differences by altering EFG1 expression to establish optimal survival strategies. We show that the overall process is governed via modulation of epigenetic regulators of chromatin structure.

Keywords: Candida albicans, Colonization, Fungal pathogen, Microbiota, Efg1p, Evolutionary game theory, Mathematical modeling

\section{Background}

By colonizing the human gastrointestinal tract as a component of the normal microbiota [1], the opportunistic fungal pathogen Candida albicans establishes a reservoir from which it can disseminate to cause systemic candidiasis. In an immunocompromised patient, the fungus is capable of escaping from the gastrointestinal (GI) tract, reaching the bloodstream and infecting deep organs, producing a life-threatening disseminated infection [2-8]. In contrast, in an immunocompetent

\footnotetext{
* Correspondence: edda.klipp@rz.hu-berlin.de; carol.kumamoto@tufts.edu ${ }^{1}$ Theoretische Biophysik, Humboldt-Universität zu Berlin, Invalidenstraße 42, D-10115 Berlin, Germany

${ }^{2}$ Graduate Program in Molecular Microbiology, Sackler School of Graduate Biomedical Sciences and Department of Molecular Biology and Microbiology, Tufts University, Boston, MA 02111, USA

Full list of author information is available at the end of the article
}

host, the organism remains as a benign commensal within the gut. Colonization of the GI tract is controlled by interaction between the host's immune system [8-19], resident intestinal microbiota [5, 6, 20-23], and the fungus [24-29].

We previously identified $C$. albicans transcription factor Efg1p as a regulator of GI colonization [26, 30]. Furthermore, in wild type (WT) C. albicans cells recovered from organs of infected mice, mRNA levels of EFG1 in cells colonizing immunodeficient mice were lower than levels in cells colonizing immunocompetent mice [26]. Since Efg1p is an important regulator of C. albicans physiology [31-35] and gene expression [34, 36-40], the difference in its expression may represent an important first step in the progression toward disease in the compromised host. 
In this communication, we present a mathematical model that describes the dynamics of colonization by $C$. albicans cells expressing either high or low levels of EFG1. The goal of the work was to demonstrate the existence of host-responsive mechanisms that regulate the expression of EFG1 during colonization. We employed principles of evolutionary game theory to model this host-pathogen interplay. Game theory is a mathematical way to study decision-making and has previously been applied to study biological systems, for instance, when studying $C$. albicans survival strategies upon macrophage attack [41]. Evolutionary game theory is applied to biological systems to predict outcomes based on the frequency and efficacy of different strategies present within a population. Game theory breaks a situation down into a set of interacting entities, termed players, a set of strategies available to those players, and a payoff to each player based on each combination of strategies. In evolutionary game theory, the payoffs represent relative differences in fitness, which influence reproduction and survival. Using these principles we constructed a game theoretical model to describe the interaction between C. albicans and its host.

Results from our modeling approach strongly support a model where at least two mechanisms contribute to shaping the C. albicans population. First, selective forces from the GI tract environment favor cells with higher Efg1p activity; this selective force is reduced in an immunodeficient host. This mechanism does not require a response of $C$. albicans to the host environment. Second, individual cells change from high Efg1p activity to low Efg1p activity in response to the GI tract environment. In this case, a difference in the environment is sensed, resulting in a change in gene expression. We demonstrate that during colonization of the host, C. albicans regulates the expression of several activities that control chromatin structure. Our data, in combination with mathematical modeling, strongly suggest that $C$. albicans responds to immune activities of the host by establishing optimal survival strategies via altering the machinery that controls gene expression.

\section{Results}

\section{Modeling based on evolutionary game theory}

We previously reported that EFG1, encoding a basic helix-loop-helix (bHLH) transcription factor, is differentially regulated in hosts with varying immune activity [26]. To study the mechanisms that gave rise to differences in EFG1 expression during colonization, we undertook a quantitative analysis of colonization data using mathematical modeling based on the principles of evolutionary game theory. In this model, the players are $C$. albicans and the host and each has two available strategies (Additional file 1: Figure S1A). The strategies available to $C$. albicans cells are high Efg1p activity (denoted $h$ ) and low Efg1p activity (denoted $l$ ). The strategies available to the host are basal (denoted $b$ ) or activated (denoted $a$ ). As a result, there are 4 possible combinations of individual fungal cell and host cell strategies (Fig. 1a). For each fungal cell and host cell undergoing an interaction, there is a payoff value, $\pi$, which depends on the combination of fungal and host strategies. The values for the 4 payoffs, $\pi$, to $C$. albicans cells (Fig. 1a) depend on the strategy chosen by the fungal cell and the host cells. Similarly, there are 4 payoffs, $\pi$, to the host (Fig. 1a) that depend on the strategy used by the host cell and the C. albicans cell.

Within an individual host, changes in fungal and host cell populations during colonization (Additional file 1: Figure S1) were modeled using a set of ordinary differential equations that incorporated the 4 different payoffs to $C$. albicans and the 4 different payoffs to the host. The following equation was used to describe the C. albicans population during colonization:

$$
\dot{x}_{l}=x_{l}\left(1-x_{l}\right)[\bar{\pi}(l, y)-\bar{\pi}(h, y)]+\varepsilon\left(1-x_{l}\right)
$$

where $x_{l}$ denotes the proportion of low Efg1p activity cells in the population, $y$ denotes the proportion of host cells that are activated or basal $\left(y_{\mathrm{a}}\right.$ or $\left.y_{\mathrm{b}}\right), \bar{\pi}(i, y)$ denotes the average payoffs to $C$. albicans cell type $i$ (either $l$ or $h$ ) depending on host strategy $j$ (either $b$ or $a$ ) corrected for the fraction of the host population using that strategy $\left(y_{j}\right)$, and $\varepsilon$ denotes the rate at which $C$. albicans cells change from high Efg1p activity to low Efg1p activity. The first terms on the right side of Eq. 1 relate to the proportion of cells with low and high Efg1p activity (with $x_{h}=1-x_{l}$ ), the expression in square brackets relates to differences in average payoffs and the last term takes into account changes of individual $C$. albicans cells from high to low Efg1p activity. The derivation of this equation is based on [42] and described in Additional file 2.

Similarly, the following equation was used to model the responses of the host to C. albicans during colonization:

$$
\dot{y}_{a}=y_{a}\left(1-y_{a}\right)[\bar{\pi}(a, x)-\bar{\pi}(b, x)]
$$

In Eq. 2, $y_{a}$ denotes the proportion of host cells using the activated immune response strategy, $x$ indicates the proportion of fungal cells that are in the low or high Efg1p activity state $\left(x_{l}\right.$ or $\left.x_{h}\right)$, and $\bar{\pi}(j, x)$ are the average payoffs to the host cells depending on the strategy of the C. albicans cells corrected for the fraction of the fungal population using that strategy. The derivation of this equation is analogous to Eq. 1. The final output of this model will be a description of the proportion and type of cells in the fungal and host populations over time during colonization. 


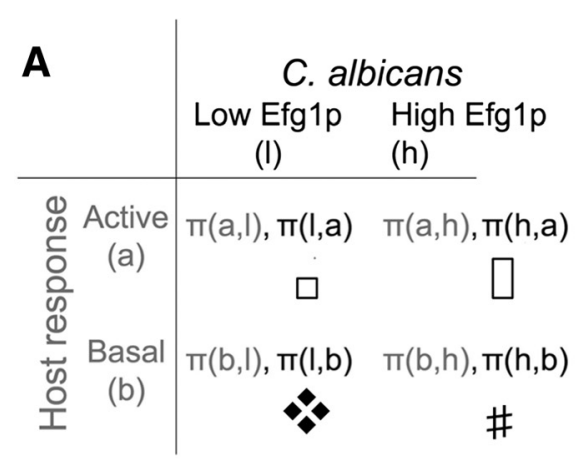

B $\triangle e f g 1 / A C T 1 p r-E F G 1$

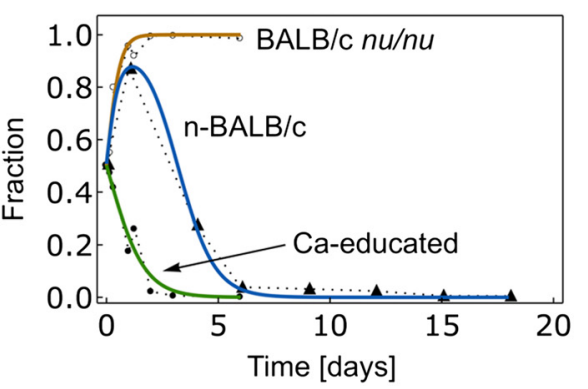

\section{C}

$\triangle e f g 1 /$ WT
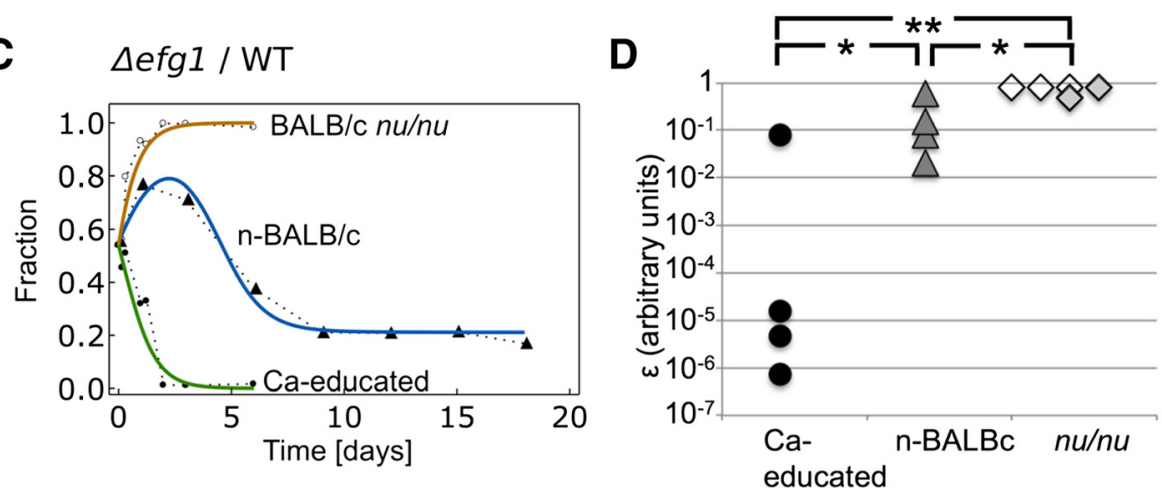

Fig. 1 Model simulations of C. albicans population dynamics follow experimental results. Panel a: Payoffs for C. albicans (black letters or pictures) and host cells (grey letters) as a result of their interactions are illustrated in the table. For each combination of fungal and host cell strategies, there is a payoff to the fungal cell (shown as a picture) and a payoff to the host cell (not depicted). Panels $\mathbf{b}$ and $\mathbf{c}$ : The fraction of low-EFG1 cells is plotted as a function of time of fecal pellet collection. Averaged experimental data are shown as symbols connected by dotted lines. Open circles, BALB/c nu/nu mice; closed triangles, n-BALB/c mice; closed circles, Ca-educated BALB/c mice. Simulations generated with the model are shown in bolded lines. Orange, BALB/C nu/nu mice; blue, n-BALB/c mice; green, Ca-educated BALB/c mice. Panel b: Competition between $\Delta$ efg 1 null mutant and ACT1pr-EFG1 strains of C. albicans. Values for parameters (in arbitrary units) were as follows: for the hosts $\pi(a, l)=1.75, \pi(b, l)=$ $0.00071, \pi(a, h)=9.25, \pi(b, h)=0.0063$, and for fungi $\pi(l, a)=0.12, \pi(l, b)=3.33, \pi(h, a)=1.34, \pi(h, b)=0.0067$. Panel c: Competition between $\Delta$ efg 1 null mutant and WT C. albicans strains. Values for parameters were: for the hosts $\pi(a, l)=1.75, \pi(b, l)=0.00071, \pi(a, h)=0.086, \pi(b, h)=0.12$, and for fungi $\pi(l, a)=0.12, \pi(l, b)=3.33, \pi(h, a)=1.47, \pi(h, b)=2.91 ; \varepsilon_{\text {Ca-educated }}=2.57 \times 10^{-5}, \varepsilon_{n-B A L B / C}=2.86 \times 10^{-1}, \varepsilon_{\text {nu/nu }}=9.65 \times 10^{-1}$. Panel d: Using the data from individual mice, values for $\varepsilon$ (in arbitrary units) were extracted. Each symbol indicates the average value of $\varepsilon$ for colonization of an individual mouse. Ca-educated BALB/c mice (black circles); n-BALB/c mice (grey triangles); BALB/c nu/nu mice (open diamonds); Ca-educated BALB/ c nu/nu mice (grey diamonds). ${ }^{*}, p<0.05 ;{ }^{* *}, p<0.01$

In vivo colonization dynamics data used for the modeling Our evolutionary game theory model was partially supported with published in vivo data [26]. In addition, we generated a new set of data that reports on C. albicans colonization in mice with differing levels of immune response. These experiments were specifically designed for the needs of the model. We measured changes in fungal populations that occurred during colonization of either immunodeficient mice or previously challenged, "Ca-educated" mice. We considered competition between $C$. albicans cells with no EFG1 expression versus C. albicans cells with EFG1 expression in mice with three levels of immunity: 1) naive immunocompetent mice, with no experience of $C$. albicans colonization, referred to as n-BALB/c mice; 2) "Ca-educated" BALB/ C mice, which exhibit a restrictive GI tract environment because they were previously challenged with $C$. albicans; 3) BALB/c nu/nu mice, which are immunodeficient due to their lack of $\mathrm{T}$ cells.

Ca-educated mice were produced by oral inoculation of BALB/c mice with C. albicans, which results in protective immune responses against orally or intravenously inoculated $C$. albicans [11, 43-50]. Ca-educated $\mathrm{BALB} / \mathrm{c}$ mice were used because their GI tract environment was "restrictive" due to the immune response of the host, the effects of microbiota or both. A restrictive GI tract environment has previously been shown to favor EFG1-expressing cells over cells lacking Efg1p [26] which was a foundation for our modeling studies. $\mathrm{BALB} / \mathrm{c} n u / n u$ mice are unable to suppress fungal colonization, carry a different microbiota [21] and have a "permissive" GI tract environment. Under the conditions 
of these experiments, $n u / n u$ mice did not develop deepseated or mucosal fungal infection, but were preferentially colonized by low-EFG1-expressing C. albicans populations [26].

In the studies described here, mice were inoculated by oral gavage with equal numbers of $\Delta e f g 1$ cells and cells either overexpressing EFG1 under the $A C T 1$ promoter (denoted by ACT1pr-EFG1) or WT cells expressing EFG1 from the native promoter. Following inoculation with either of the mixes, relative colonization was monitored in fecal pellets (see Materials and Methods), which was previously shown to correlate well with colonization measured in the lower GI tract [28].

The results of these studies showed that in $\mathrm{Ca}$ educated BALB/c mice, $\Delta e f g 1$ cells were out-competed by both types of EFG1-expressing cells (Fig. 2a,b, closed black symbols); out-competition by the $\Delta e f g 1$ strain was not observed at any time point measured. Total levels of colonization by either of the two mixes also declined over time (Additional file 3: Figure S2). Inoculation of n$\mathrm{BALB} / \mathrm{c}$ mice resulted in an initial out-competition by the $\Delta$ efg1 mutant relative to either type of EFG1-expressing strain, although $\Delta e f g 1$ cells were eventually outcompeted after $\sim 9$ days of colonization ([26]; summarized in Fig. 1b,c). In contrast, the $\Delta e f g 1$ strain was able to out-compete both ACT1pr-EFG1 cells (Fig. 2a, open symbols) and WT C. albicans cells (Fig. 2b, open symbols) in immunodeficient $n u / n u$ BALB/c mice. Total levels of colonization were high in these mice (Additional file 3: Figure S2). When immunodeficient mice previously challenged with $C$. albicans (Ca-educated BALB/c mice $n u / n u$ - not able to play strategy $a$ ) were inoculated with the mixture, the $\Delta e f g 1$ null mutant strain outcompeted WT cells (Fig. 2b, grey diamonds). This result contrasted with the results for Ca-educated BALB/C mice (constantly playing strategy $a$ ) inoculated with the same C. albicans mixture (Fig. 2b, closed triangles). In summary, the data showed that mixed populations of $\triangle e f g 1$ and EFG1-expressing cells reached different final compositions depending on the immune status of the host.

The outcompetition by EFG1-expressing cells in Caeducated BALB/c mice is proposed to reflect, at least partially, the activity of the host immune response. To show that immune responses were activated in response to $C$. albicans colonization, IL-17A and IL-22 cytokine expression in GI tract organs was measured. Cytokines in mice not colonized with $C$. albicans were also measured. These cytokines were chosen for analysis because previous studies showed that colonization resulted in up-regulation of their expression in the murine stomach [8, 51-53], the best studied site of interaction between C. albicans and GI tract tissue, as well as in other GI organs $[8,51]$. We therefore extracted RNA from stomach tissue of mice colonized (or not) with C. albicans for 20 days and measured gene expression by real time RTPCR (qRT-PCR). Uninoculated mice expressed relatively low levels of cytokine IL-17A, both at day 0 of the experiment (i.e., the day of inoculation, Fig. 3a open squares) and 20 days later (Fig. 3a, open circles). The same held true for cytokine IL-22 (Fig. 3b, open squares and circles respectively). Mice colonized with C. albicans for 20 days, the length of time used to generate Ca-educated BALB/c mice, expressed higher levels of IL-17A (Fig. 3a, closed diamonds) and IL-22 (Fig. 3b, closed diamonds). These results demonstrated that an immune response was mounted in $C$. albicans-colonized BALB/c mice.

Further, we proposed that $\mathrm{CD} 4+\mathrm{T}$ cells would be a necessary part of a restrictive GI tract environment. The results of competitions in BALB/c nu/nu mice showed that $\mathrm{T}$ cells are required to generate a restrictive GI tract environment (Fig. 2b). To test for an ongoing role for $\mathrm{CD} 4+\mathrm{T}$ cells, mice were first Ca-educated and then injected intraperitoneally with either anti-CD4 antibody, to deplete CD4+ T cells [46], or with isotype control antibody. The treated mice were orally inoculated with a mixture of $\Delta e f g 1$ null and WT cells, and colonization by the two strains was monitored over time. The normal outcompetition by WT cells was not observed in $\mathrm{Ca}$ educated mice treated with anti-CD4 antibody (Fig. 2c). Therefore, the results supported the model that the restrictive environment created by $\mathrm{Ca}$-education was at least partially due to an immunological response. In summary, activity of the host immune system promotes colonization by fungal cells expressing EFG1, whereas an immunodeficient host favors $\triangle e f g 1$ null cells.

\section{Parameter estimation}

Equations 1 and 2 were used to simulate the behavior of C. albicans cells during GI colonization in mice. During the parameterization process, we postulated that in any host fungal fitness in response to a particular host strategy was the same.

To use the mathematical model to simulate colonization dynamics, we estimated values (in arbitrary units) for each of the eleven unknown parameters in the model: the four payoffs for the C. albicans cells, the four payoffs for the host cells, and three different values for $\varepsilon$ describing rates of change from high to low Efg1p activity in each of the

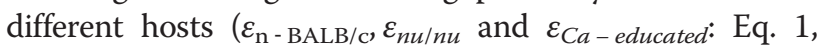
Fig. 1a). Parameter estimation was conducted by fitting the model to the averaged experimental data shown in Fig. 1b,c or from our previous study [26] using the tool COPASI and its built-in Evolutionary Programming parameter estimation routine [54]. The parameter estimation results showed that different parameter sets successfully simulated the data. Therefore, we completed 1000 


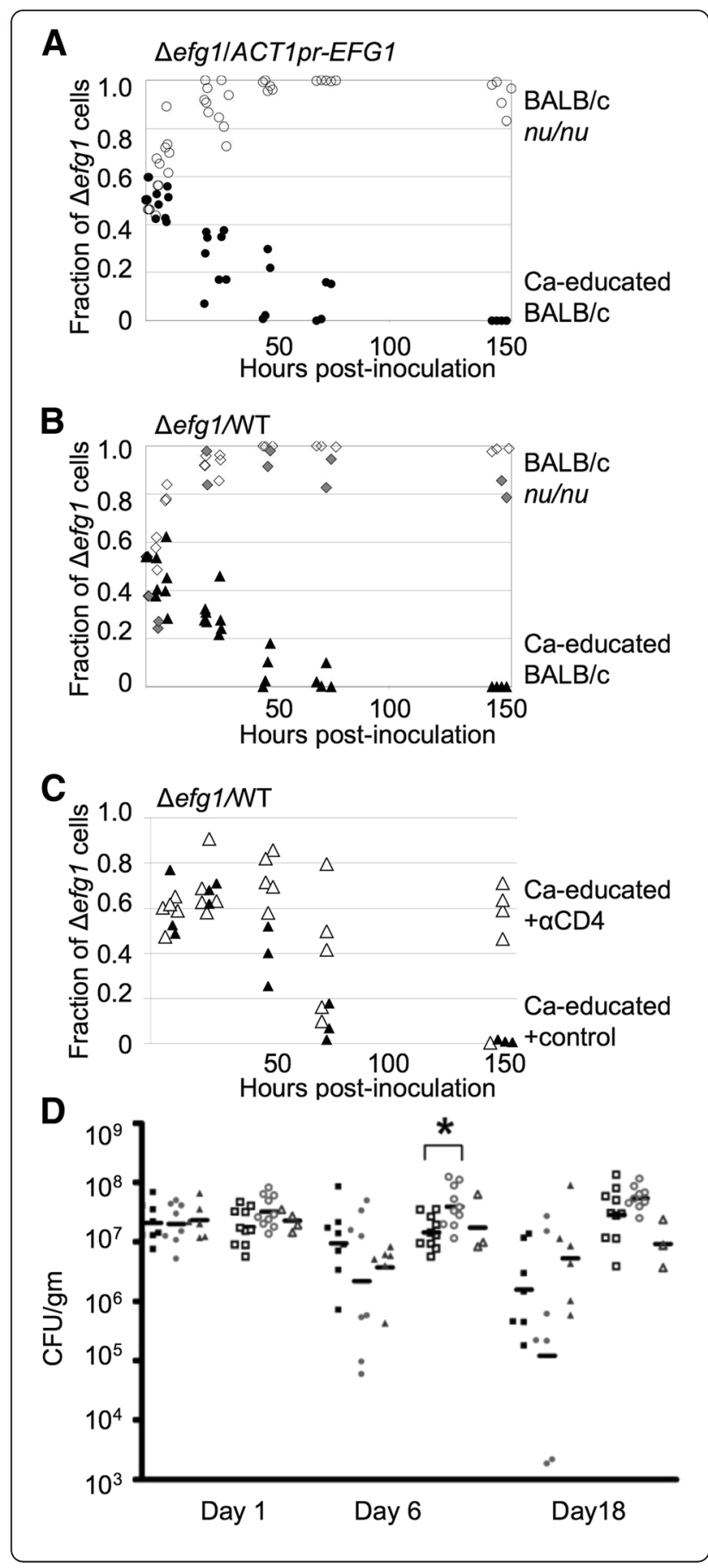

Fig. 2 Competition between cells with or without EFG1. Colonization dynamics of mixed populations of $C$. albicans were measured in Ca-educated mice (black circles or triangles) or BALB/c nu/nu mice (open or grey circles or diamonds). Panels $\mathbf{a}, \mathbf{b}$, and $\mathbf{c}$ show the fraction of $\Delta$ efg 1 null mutant cells in either of the mixed populations in fecal pellets as a function of time. Each symbol indicates a sample from an individual mouse. Panel a: Competition between $\Delta$ efg 1 and ACT1pr-EFG1 cells. Closed circles, Ca-educated BALB/c mice. Open circles, BALB/c nu/nu mice. Panel b: Competition between $\Delta$ efg1 and WT cells. Closed triangles, Ca-educated BALB/c mice. Open diamonds, BALB/c nu/nu mice. Grey diamonds, Ca-educated BALB/C nu/nu mice. Panel c: Competition between $\Delta$ efg 1 and WT cells. Open triangles, Ca-educated BALB/c mice treated with anti-CD4 antibody. Closed triangles, Ca-educated BALB/c mice treated with isotype control antibody. Panel $\mathbf{d}$ : Levels of $C$. albicans in fecal pellets collected on day 1,6 or 18 post-inoculation from orally inoculated mice. Squares, WT C. albicans; circles, $\Delta \sin 3$ null mutant; triangles, $\Delta \sin 3 / S / N 3^{+}$complemented strain. Closed symbols, n-BALB/C mice; open symbols, BALB/c nu/nu mice

parameter estimation runs and visually inspected the model simulations for a number of fits. We noted that parameter sets with residual sum of squares (RSS) less than 0.07 approximated the data points well. Therefore, we performed further studies using parameter sets that gave RSS values smaller than 0.07 (393 total parameter sets). We plotted the distributions of fungal payoffs from the 393 parameter sets and, in most cases, did not observe large variations in fungal payoff estimates (Additional file 4: Figure S3A). We also performed correlation coefficient analysis for fungal payoffs. A high correlation in fungal payoff values was observed for fungi playing against a fixed host strategy (Additional file 4: Figure S3B). Using a representative set of parameters, we show that the model was able to simulate the experimental data (Fig. 1b,c).

\section{Estimated payoffs to fungal cells are in agreement with predictions based on experimental results}

The relative values of the parameters in the payoff matrix (Fig. 1a) determine the overall dynamics of the competition between high and low Efg1p activity cells. Therefore, we examined how well the predicted relative values for payoffs to $C$. albicans corresponded to the experimentally known behavior of cells during colonization. The four fungal payoff values in a given parameter set were arranged from lowest to highest; this ordered sequence of payoff values is termed a motif. Each of the 393 parameter sets with RSS $<0.07$ was analyzed and the observed frequencies for the various motifs are shown in Table 1. Although the values for parameters in different parameter sets were not identical, two parameter orders accounted for over $90 \%$ of the parameter sets that successfully simulated the data. Therefore, most of the successful parameter sets exhibited similar features. 

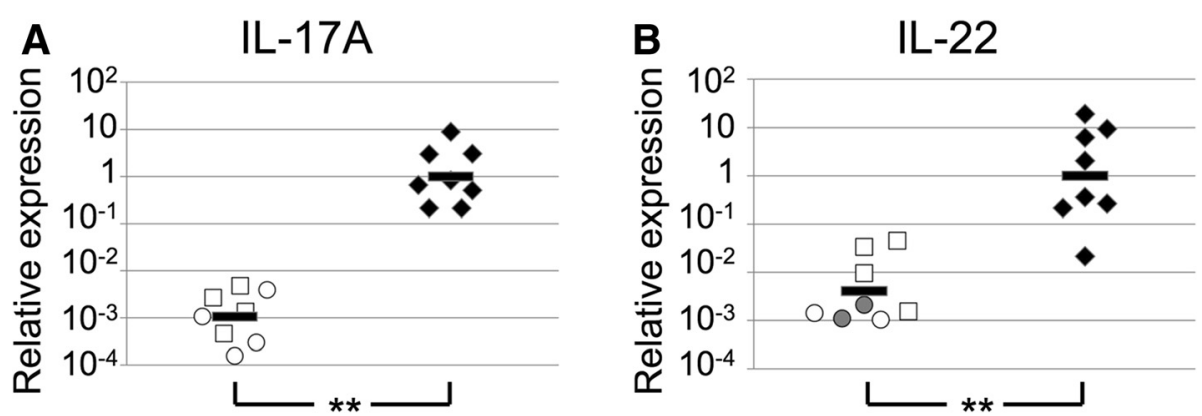

Fig. 3 Expression of cytokines in Gl tract tissue. Mice were orally inoculated with WT C. albicans and sacrificed 20 days later. Additional mice did not receive C. albicans inoculation and were sacrificed either on the day of inoculation (day 0) or on day 20. Expression of cytokines IL-17A (panel a) and IL-22 (panel $\mathbf{b}$ ) in stomach tissue was measured by qRT-PCR and normalized using expression of GAPDH. Geometric mean for colonized mice was set to 1. Panels a and b: Circles, uninoculated, day 0; squares, uninoculated, day 20; filled diamonds, C. albicans colonized, day 20. Grey circles, samples with undetectable signal. Bar shows the geometric mean. ${ }^{*}, p<0.0001$ ( $t$ test with log-transformed data)

The symbol will be used to indicate the payoff to $C$. albicans when the fungus is expressing low levels of EFG1 and the host is using the basal strategy. \# will be used to indicate the fungal payoff when C. albicans is expressing EFG1 highly and the host is using the basal strategy. When the host is using the activated strategy, C. albicans expressing EFG1 at low levels will receive payoff $\square$ and C. albicans expressing EFG1 highly will receive payoff $\square$.

For the C. albicans population composed of $\Delta e f g 1$ and WT cells, 6 motifs were observed and the two most common were $\square<\square<\#<*$ (frequency
$66 \%$ ) and $\square<\#<\square<$ (frequency $29 \%$ ) (Table 1 and Fig. 1a). The structures of these motifs agreed well with experimental expectations (Fig. 2 and $[26,30])$. Based on experimental results, the greatest payoff for C. albicans (allowing highest colonization) should occur in either of the following two situations. In the first situation, $C$. albicans cells with low EFG1 expression $(l)$ colonize a naïve host (strategy $b$ ) to high levels (Fig. 2, open symbols), presumably because the host immune response is too weak to kill the fungus, resulting in high payoff to C. albicans. In the second

Table 1 Fungal parameter motifs

\begin{tabular}{|c|c|c|c|}
\hline$\Delta e f g 1 / \mathrm{WT}$ & & $\triangle e f g 1 / A C T 1 p r-E F G 1$ & \\
\hline Motifa & $\begin{array}{l}\text { Frequency } \\
(\%)^{b}\end{array}$ & Motifa & $\begin{array}{l}\text { Frequency } \\
(\%)^{\mathrm{b}}\end{array}$ \\
\hline$\square<\square<\#<*$ & $66 \%$ & $\#<\square<\square<*$ & $66 \%$ \\
\hline$\square<\#<\square<*$ & $29 \%$ & $\square<\#<\square<*$ & $26 \%$ \\
\hline$\#<<<\square<\square$ & $2.5 \%$ & $\square<\square<\#<*$ & $3.1 \%$ \\
\hline$\#<\square<<<\square$ & $1.3 \%$ & $\#<<<<\square$ & $2.5 \%$ \\
\hline$\square<\#<<<$ & $0.76 \%$ & $\#<\square<<<$ & $2.0 \%$ \\
\hline$\#<\square<\square<*$ & $0.25 \%$ & & \\
\hline
\end{tabular}

${ }^{a}$ Description of fungal payoff motifs. $\downarrow$, C. albicans low EFG1, host basal; \#, C. albicans high EFG1, host basal; $\square$, C. albicans high EFG1, host activated; $\square$, C. albicans low EFG1, host activated

${ }^{\mathrm{b}}$ The frequency of each type of parameter order 
situation, C. albicans cells in the high Efg1p activity state (h) resist killing in a host with a stronger immune response (strategy $a$ ) and colonize well (Fig. 2, closed symbols), resulting in high payoff 7 . In either situation, $C$. albicans is well adapted to the host environment. Therefore, in a host with an activated immune response, the payoff should be greater for a C. albicans cell with high Efg1p activity ( $\square$ ) than one with low Efg1p activity $(\square)$, i.e. $\square>\square$, while in a naïve host, low Efg1p activity should give a higher payoff ( $)$ than high Efg1p activity $(\#)$, i.e., $>$, and indeed, this is observed in all six motifs (Table 1). Further, in the top two motifs for each competition, colonization of the naïve host by cells with low Efg1p activity state, $(*)$, results in the largest payoff value, arguing that the situation is maximally advantageous to $C$. albicans when the host is immunocompromised.

Additionally, in the two most common motifs, \# is larger than $\square$, i.e., cells with high Efg1p activity in a naïve host are better off than cells with low Efg1p activity that are colonizing a host with a stronger immune response. This prediction agrees well with experimental results because when the host has mounted an activated immune response, low Efg1p activity cells may be preferentially killed (Fig. 1b,c, green and blue line). Moreover, the smaller payoff $\square$ implies that there is a larger penalty associated with having the low Efg1p activity state $(l)$ when the host is using the activated immune response $(a)$, compared to the penalty for having the high Efg1p state (h) when the host is using a naïve immune response (b).

For the $\triangle e f g 1 / A C T 1 p r-E F G 1$ population, the payoff values were classified into five different motifs (Table 1) and the two most common were:

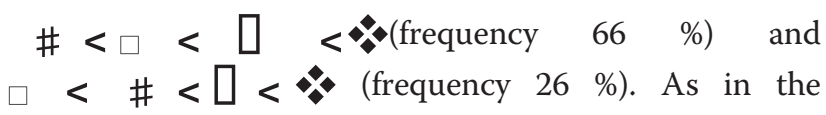
$\Delta e f g 1 / \mathrm{WT}$ competition, it holds true that $\square>\square$ and $>$ \# in all five motifs. Again, in terms of fungal payoffs, this inequality implies that in a host with an activated immune response, $C$. albicans cells with high Efg1p activity are more fit, whilst in a naïve host, cells with low Efg1p activity are favored. Payoff to fungal cells with high Efg1p activity in n-BALB/c mice (using strategy $b$ ) was relatively small for the $\Delta e f g 1 /$ ACT1pr-EFG1 competition in comparison to the $\Delta e f g 1 /$ WT competition. This difference in the payoff is consistent with the finding that at early timepoints post-inoculation of $\mathrm{n}-\mathrm{BALB} / \mathrm{c}$ mice, the ACT1pr-EFG1 strain colonizes poorly relative to WT cells [26]. If we omit this payoff (\#), the most common motifs for the two competitions are identical. Thus, when the model successfully simulated the experimental data $(\mathrm{RSS}<0.07)$, the relative values in the payoff matrix showed good correspondence with the experimentally determined behavior of $C$. albicans cells.
The rate at which C. albicans changes from high to low Efg $1 p$ activity states is predicted to be greater in a host with a weak immune response

Equation 1 includes a term $\varepsilon\left(1-x_{l}\right)$ that takes into account the effect of changes in Efg1p activity that may occur in individual WT C. albicans cells. To detect the contribution of changes in Efg1p activity in individual cells to colonization dynamics, we repeated the parameter estimation using data for competitions in individual mice (as depicted in Fig. 2b). Using this approach, we asked how $\varepsilon$ values varied between mice as a result of their individual immune responses. To determine values for $\varepsilon$ we fitted parameters for the $\Delta e f g 1 /$ WT competition for each mouse individually (four Ca-educated mice, three BALB/c nu/nu mice, two Ca-educated BALB/c nu/ $n u$ mice and four n-BALB/c mice [26]). Each parameter set that simulated the $\Delta e f g 1 / \mathrm{WT}$ competition dynamics for an individual mouse and also simulated the averaged data (shown in Fig. 1c) was considered successful. Next, the median RSS value for each mouse was used as the threshold for accepting parameter sets for further analysis. From these accepted parameter sets, we extracted values for $\varepsilon$, the rate at which cells change from high Efg1p activity to low Efg1p activity. The $\varepsilon$ values were then averaged and plotted in Fig. 1d. Including a term for the converse event, changing from low Efg1p activity to high, did not improve the model fit and this event was ignored. This event may be negligible because at the start of the experiment, few WT cells were in the low EFG1 state [26]).

In Ca-educated mice, the predicted rate at which cells changed from high to low Efg1p activity, $\varepsilon_{\text {Ca-educated }}$, was relatively low (Fig. 1d). In contrast, in $n-B A L B / c$ mice, the rate $\varepsilon_{\mathrm{n}-\mathrm{BALB} / \mathrm{c}}$ (averaged over the 18-day time course) was higher (Fig. $1 \mathrm{~d}, p<0.027, t$-test with $\log$-transformed data). The highest rate of change, $\varepsilon_{n u / n u}$, was predicted to occur during colonization of BALB/c mice $n u / n u$ (Fig. 1d; $p<0.019$ vs $\mathrm{n}-\mathrm{BALB} / \mathrm{c}$ mice and $p<0.0037$ vs Caeducated mice; $t$-test with log-transformed data). Therefore, we observed an inverse relationship between the strength of the host immune response and $\varepsilon$.

We also tested the effects of setting $\varepsilon$ to either zero or a non-zero constant value. Using simulation, we found that the fit of the model to the experimental data was poor under these conditions (Additional file 5: Figure S4). Therefore, the modeling predicted that the rate at which WT cells alter EFG1 expression was not constant; rather, the rate of change differed depending on host immune status.

\section{Regulators of EFG1 expression are differentially expressed based on host immune status}

Our modeling results support the idea that individual $C$. albicans cells change from high Efg1p activity to low 
Efg1p activity at different rates depending on the GI tract environment. We therefore hypothesize that changes in the environment are sensed, resulting in altered gene expression. To further validate this point, we measured the expression of factors that regulate Efg1p. RNA from WT C. albicans cells harvested from the ceca of Ca-educated, n-BALB/c, and BALB/c nu/nu mice on day 2 post-inoculation was extracted, and qRT-PCR was performed. As before [26], expression of EFG1 was lower in C. albicans cells recovered from BALB/c nu/nu versus Ca-educated BALB/c mice (Fig. 4a). At this early time point, EFG1 expression in n-BALB/c mice was variable. We next studied expression of a collection of genes whose products regulate the activity of Efg1p. TPK1, $B C Y 1, R A S 1, P D E 2[55,56]$ and $F L O 8$, whose product functions with Efg1p [57], showed lower expression in the immunodeficient host (Fig. 4a). RAS1 $\left(\mathrm{R}^{2}=0.63\right)$ and PDE2 $\left(\mathrm{R}^{2}=0.7\right)$ expression correlated well with EFG1 expression (Additional file 6: Figure S5).

EFG1 expression is also influenced by activities of several histone modification complexes [58-60]. Therefore, we determined the expression levels of these genes in $C$. albicans cells derived from colonized mice with varying immune status. Consistent with the determined rates of change for EFG1 expression in response to the GI tract environment (Fig. 1d), we observed a trend in the expression levels of EFG1 regulators depending on host immune status. HDA1, SET3, HOS2, SIN3, and RPD3 encode components of histone deacetylase complexes (HDAC) and they are known to regulate the expression of EFG1 [58-60]. Transcript levels for these genes and for the co-repressor gene TUP1 were 2-3-fold lower in C. albicans cells colonizing BALB/c nu/nu mice in comparison with cells colonizing Ca-educated mice (Fig. 4b). TUP1 $\left(\mathrm{R}^{2}=0.72\right)$ and RPD3 $\left(\mathrm{R}^{2}=0.71\right)$ expression correlated well with EFG1 expression (Additional file 6: Figure S5). A classical role of HDAC proteins is transcriptional repression as a result of more closed and compact chromatin state [61]. In contrast to HDACs, histone acetyltransferases (HATs) are commonly found to enhance transcription [61]. For example, Efg1p recruits some HATs to promoters of hyphae-specific genes, up-regulating their expression [62]. Expression of HAT genes was also regulated in a host statusdependent manner. HAT genes ESA1 and SAS2 [62, 63] were expressed at 5 to 7 -fold lower levels during colonization of BALB/c $n u / n u$ mice (Fig. 4c), conditions in which EFG1 expression decreased from high to low at a faster rate (Fig. 1d). ESA1 $\left(\mathrm{R}^{2}=0.68\right)$ and YNG2 $\left(\mathrm{R}^{2}=\right.$ $0.59)$ expression correlated well with EFG1 expression (Additional file 6: Figure S5). These observations suggest that regulation of gene expression through the function of HAT and HDAC complexes plays a role in finding optimal strategies during host-pathogen interactions.

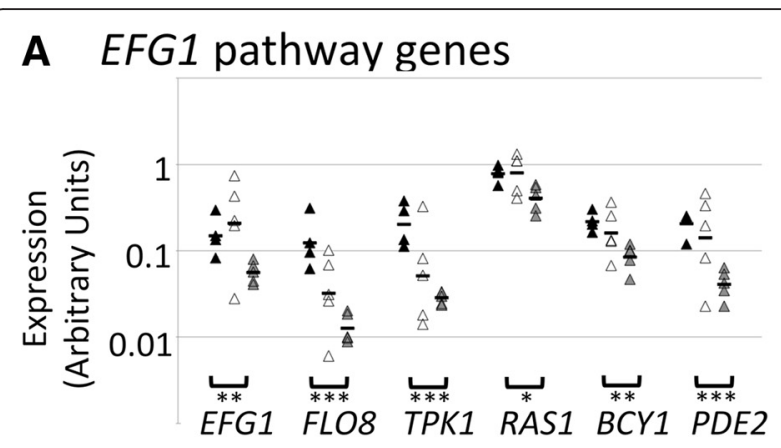

\section{B HDAC complex genes}

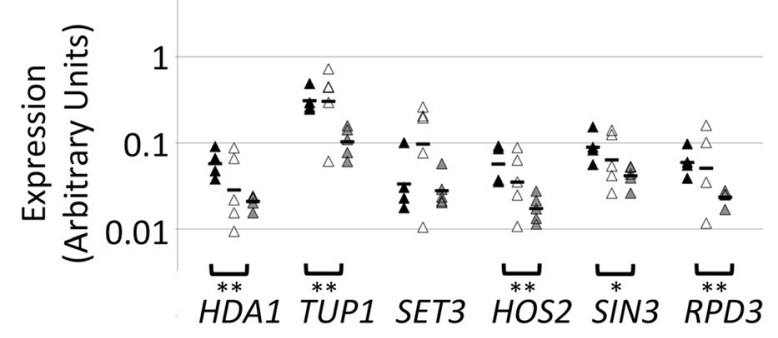

\section{HAT genes/Control genes}

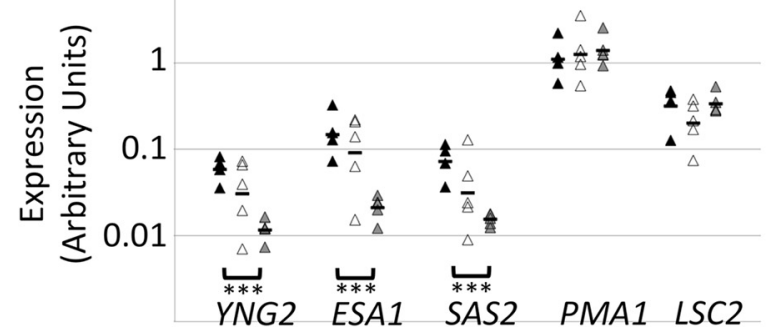

Fig. 4 Expression of genes in $C$. albicans cells colonizing mice of different immune status. Ca-educated (black symbols), n-BALB/c mice (open symbols) and BALB/c mice nu/nu (grey symbols) were orally inoculated with C. albicans. On day 2 post-inoculation, C. albicans cells were harvested and gene expression in these cells was measured by quantitative RT-PCR. The experiment was performed twice and representative results are shown. Brackets indicate comparisons between expression in Ca-educated mice versus BALB/c nu/nu mice. ${ }^{*}, p<0.05$; ${ }^{* *} p<0.01 ;{ }^{* * *} p<0.001$ ( $t$ test with log-transformed data). Expression of the following genes is shown: Panel a: EFG1, FLO8, TPK1, RAS1, BCY1 and PDE2. Panel b: HDA1, TUP1, SET3, HOS2, SIN3, and RPD3. Panel c: YNG2, ESA1, SAS2, PMA1 and LSC2

Finally, as expected, housekeeping genes PMA1, and $L S C 2$ were expressed at similar levels in cells colonizing different hosts (Fig. 4c). Therefore, in addition to Efg1p, several proteins that function in the Efg1p pathway showed differential expression depending on host immune status.

\section{Altered colonization dynamics in the absence of HDAC subunit Sin3p}

These results indicated that histone modifying activities might play a role in modulating colonization. To test 
this model, we constructed and studied mutants lacking SIN3, encoding a subunit of a histone deacetylase complex. Both SIN3 and RPD3, encoding the catalytic subunit of the Sin3p complex, showed host status dependent differences in gene expression (Fig. 4). Further, EFG1 expression was lower during exponential growth of C. albicans cells in the absence of Rpd3p [59]. Therefore, we constructed a homozygous $\Delta \sin 3$ null mutant in which both copies of SIN3 were deleted, and then complemented the mutation by reintroducing one copy of SIN3 into the null mutant at its native locus.

To measure the effects of the $\Delta \sin 3$ mutation on colonization, $\mathrm{n}-\mathrm{BALB} / \mathrm{c}$ and $\mathrm{BALB} / \mathrm{c} n u / n u$ mice were colonized with WT, $\Delta \sin 3$ null, or the complemented strain. Overall, as previously observed [26, 44], colonization was higher in mice lacking $\mathrm{T}$ cells for all strains when compared to the levels in a WT host. At day one post-inoculation, there was no difference in colonization between WT and the $\Delta \sin 3$ strain in either a healthy or a T cell deficient host (Fig. 2d). $\Delta \sin 3$ cells showed higher levels of colonization at day 6 postinoculation, relative to WT C. albicans, in BALB/c nu/ $n u$ mice (Fig. $2 \mathrm{~d} ; p<0.012$ ). This phenotype was reversed by complementation. Hyper-colonization by the $\Delta \sin 3$ mutant strain was not observed in $\mathrm{n}$-BALB/c mice. These observations showed that the $\Delta \sin 3$ mutant strain achieved high colonization in an immunodeficient mouse more rapidly than WT $C$. albicans, consistent with the model that modulation of gene expression through histone modifying activities affects colonization dynamics. Differences in EFG1 expression were not detected (data not shown) but subtle or transient differences would be difficult to detect due to the variability in $C$. albicans gene expression in different mice. We conclude that Sin3p affects the dynamics of C. albicans colonization in the GI tract.

\section{Discussion}

Central to the biology of C. albicans is its ability to colonize a healthy host as a commensal and to become an invasive pathogen in a compromised host. C. albicans populations colonizing the GI tracts of immunocompetent or immunodeficient hosts differ in expression of EFG1 (Fig. 4 and [26]). Here we argue that two mechanisms are important for shaping the fungal population in response to host immune status. One, selective forces from the host act on the fungal population. In this mechanism, fungi are passively acted on. Two, fungi respond to host immune status by altering gene expression. In this mechanism, fungi actively sense and respond to host immune status accordingly. The combined effect of both mechanisms produces the observed host status dependent difference in fungal populations.
The results of this study support the conclusion that the rate of change from high to low Efg1p activity is higher in an immunodeficient or naïve host. Production of cells with low Efg1p activity in a host with a strong immune response should be evolutionarily costly because these cells could be killed. Controlling the rate of change in Efg1p activity protects against this evolutionary cost by minimizing the number of maladapted cells produced. Thus, by regulating the rate at which cells change from high to low Efg1p activity, the fittest $C$. albicans population is produced for each type of host.

Higher expression of HAT and HDAC genes such as $R P D 3$, which is required for higher EFG1 expression in C. albicans cells [59], may result in higher expression of EFG1 during colonization. Consistent with this model, deletion of an HDAC subunit resulted in altered colonization dynamics. The effects of the $\Delta \sin 3$ null mutation on colonization could reflect transient differences in expression of EFG1 between WT and mutant cells. In particular, EFG1 expression may reach low levels sooner in $\Delta \sin 3$ null mutants during colonization of an immunodeficient host, resulting in a more rapid rise in colonization. Alternatively, since HDACs are expected to affect the expression of many genes, a number of genes may exhibit altered expression in the absence of this HDAC subunit and the sum of their effects may yield the altered colonization that was observed. These results are consistent with the model that there is a profound difference in the physiology of $C$. albicans cells colonizing an immune active, immunocompetent host versus an immunodeficient host.

Most humans are naturally colonized with Candida early in life [64] and would be expected to exhibit an "activated" response to C. albicans. Therefore, C. albicans populations colonizing healthy humans are expected to express high levels of EFG1 transcripts. If a person's immune status were to decline, the $C$. albicans population would be expected to shift so that cells express low levels of EFG1 transcripts. A change in the population resulting in a preponderance of low Efg1p activity cells may represent an early step in candidiasis. Cells lacking Efg1p were previously found to escape more readily from the GI tract in mice subjected to hypoxic shock [65]. Therefore, for WT cells, low EFG1 expression may favor escape from the GI tract and after escape, EFG1 expression may increase, permitting expression of Efg1p-dependent virulence factors and favoring the progression to disease.

In summary, our results using a mathematical model based on evolutionary game theory support the conclusion that the ability of cells to sense the immune status of the host and down-regulate Efg1p activity accordingly contributes to the adaptation of the population to the host. Evolutionary game theory allowed the analysis of 
the complex interactions between host and C. albicans cells as they changed in response to each other during the course of colonization. Since host status may decline as a result of numerous insults to the host, increasing the rate of change from high to low Efg1p activity under appropriate conditions enhances the ability of C. albicans to colonize to high level. Through differential regulation of fungal activities such as Efg1p, the physiology of the colonizing fungal population can be tightly coupled to the immune status of the host.

\section{Conclusion}

In conclusion, here we present an application of evolutionary game theory to study mechanisms important for C. albicans colonization of hosts with varying immune activities. Our modeling approach supported the idea that $C$. albicans senses host immune strength and adapts accordingly. Our mathematical model predicted that individual fungal cells were able to decrease Efg1p activity at a faster rate when colonizing an immunodeficient host. We showed that in response to host immune status, $C$. albicans regulates both up- and down-stream EFG1-related processes by altering expression of multiple histone modification enzymes involved in modulating the overall chromatin structure in the fungal cell. Taken together, our results demonstrate that $C$. albicans cells fine-tune their regulatory programs, including the Efg1p pathway, in response to host immune activities.

\section{Methods}

\section{Strains and growth conditions}

C. albicans strains used in this study are listed in (Additional file 7: Table S1). Primers used for strain construction are listed in (Additional file 8: Table S2B).

The $\Delta \sin 3$ null mutant and complemented strains were constructed using the strategy described previously [66]. Briefly, primer pairs SIN3A/SIN3B and SIN3C/ SIN3D were used to amplify sequences from the 5 and 3 regions of the SIN3 gene. These fragments were fused by overlap PCR and cloned into either the Sat placer or the Ura placer [66]. The two constructs were used to delete the two alleles of SIN3 from the chromosome of a WT strain. Integration of the constructs was verified by PCR with primers Sn3S3F/Sn3S3R for the Sat placer construct and primers Sn3U5F/Sn3U5R for the Ura placer construct. Deletion of the ORF was verified by PCR with primers $\mathrm{Sn3OF} / \mathrm{Sn} 3 \mathrm{OR}$. For complementation, the $\mathrm{SIN}^{+}$gene was amplified with primers $\mathrm{Sin} 3 \mathrm{cF} / \mathrm{Sin} 3 \mathrm{cR}$ and cloned into the Ura placer [66].

YPD (1\% yeast extract, $2 \%$ peptone, $2 \%$ glucose) and minimal CM media lacking uracil were as described [67]. Mouse inocula were grown at $37^{\circ} \mathrm{C}$ in YPD for $24 \mathrm{~h}$.

\section{GI colonization in mice}

All experiments were done in compliance with Tufts University IACUC guidelines. 5-7 week old female $\mathrm{BALB} / \mathrm{c}$ or $\mathrm{BALB} / \mathrm{c} n u / n u$ mice $(\mathrm{NCI})$ were treated with tetracycline $1 \mathrm{mg} / \mathrm{ml}$, streptomycin $2 \mathrm{mg} / \mathrm{ml}$, gentamicin $0.1 \mathrm{mg} / \mathrm{ml}$ [26]. Mice were tested for fungal contamination prior to inoculation and inoculated with $5 \times 10^{7} \mathrm{C}$. albicans cells by oral gavage. Colonization was measured in fecal pellets collected at $4 \mathrm{~h}, 8 \mathrm{~h}, 24 \mathrm{~h}, 30 \mathrm{~h}, 48 \mathrm{~h}$, 3 days and 6 days post-inoculation by homogenizing and plating [26]. The fraction of $\Delta e f g 1$ null mutant cells was

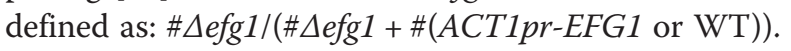

For Ca-educated mice, mice treated with antibiotics as above were inoculated by oral gavage with $C$. albicans strain SN100 (His ${ }^{-}$; a WT, genetically marked strain). Twenty days post-inoculation, antibiotics were replaced with fluconazole (60 or $120 \mathrm{ug} / \mathrm{ml}$ ) in drinking water. Following fluconazole treatment SN100 colonization declined 100-1000 fold. After 3 days, fluconazole was replaced by antibiotics (tetracycline, streptomycin, gentamicin) and 3 days later, mice were inoculated by oral gavage with mixtures of $\Delta e f g 1$ null mutant cells and EFG1-expressing cells. Colonies were counted [26] and the fraction of $\Delta e f g 1$ null mutant cells was defined as: $\# \Delta e f g 1 /(\# \Delta e f g 1+\#(A C T 1 p r-E F G 1$ or $\mathrm{WT})+\# \mathrm{SN} 100)$. The majority of the cells were derived from the second gavage. Experiments were repeated at least twice.

In some experiments, Ca-educated BALB/c mice were injected with $200 \mu \mathrm{l}$ anti-CD4 antibody (clone GK1.5, $200 \mu \mathrm{g}$, Biolegend) or $200 \mu \mathrm{l}$ isotype control (Rat IgG2b, $200 \mu \mathrm{g}$, Biolegend) intraperitoneally. Injections were given two days before and on the same day as inoculation with the mixture of two strains of $C$. albicans, as described previously [46].

Experimental data from a representative experiment with 2-3 mice per competition were averaged and used for fitting parameters. For modeling the $\Delta$ efg $1 / \mathrm{WT}$ cell population, the proportion of low Efg1p activity cells was estimated by measuring the fraction of $\Delta e f g 1$ cells, since the number of WT cells with very low Efg1p activity is initially small [26].

\section{Measurement of gene expression by quantitative RT-PCR} Ca-educated, $\mathrm{n}-\mathrm{BALB} / \mathrm{c}$ or BALB/c $n u / n u$ mice $(4-5$ per group) were inoculated with $C$. albicans by gavage. On day 2 post-inoculation, mice were euthanized and the contents of the ceca were collected [26]. Gene expression was analyzed as described [26] except that after normalization with $A C T 1$, expression is presented in arbitrary units. Primers used are listed in (Additional file 8: Table S2A ).

For measurement of cytokine gene expression, stomach tissue from $C$. albicans-colonized or uncolonized mice was frozen at $-80{ }^{\circ} \mathrm{C}$ in RNALater. RNA was 
purified with Trizol extraction and column purification, using the Ambion Purelink mini kit. DNA was eliminated with on-column DNase treatment. cDNA preparation with Superscript III and analysis of gene expression was as described [26] except that expression of GAPDH was used for normalization. Previously described primers, listed in (Additional file 8: Table S2A ), were used [68-70].

\section{Additional files}

\section{Additional file 1: Figure S1. Illustration of C. albicans-host cell} interactions. Panel A: Fungal cells are depicted as ovals. Open oval, low Efg $1 \mathrm{p}$ activity state (); closed oval, high Efg1p activity state (h). Host cells are depicted as rectangles. Open rectangle, basal state (b); closed rectangle, activated state (a). Panel B: populations of C. albicans cells (ovals) interacting with populations of host cells (rectangles). Letters indicate various conditions and arrows indicate changes in populations that occur over time. Condition A indicates a fungal population in which half of the cells have low Efg1p activity (open ovals) and half have high Efg1p activity (filled ovals). The host cells in this condition are activated (filled rectangles). This condition represents interactions occurring following inoculation of a mixed population of C. albicans cells into a Caeducated host. As shown by the data in Fig. 2, the fungal population changes over time so that almost all of the cells have high Efg1p activity as illustrated by Condition B. Condition C depicts the situation following inoculation of the same fungal population into a T cell deficient BALB/C nu/nu mouse. Due to immunodeficiency, activated host cells are not produced in the normal way during colonization (open rectangles) and the fungal population changes so that most of the cells have low Efg1p activity (depicted by Condition D). Panel C: populations of C. albicans cells interacting with populations of host cells are depicted. Letters indicate various conditions and arrows indicate changes in populations that occur over time. Condition $X$ depicts the inoculation of a mixed fungal population into an initially naive $n-B A L B / c$ mouse. Initially, the low Efg1p activity cells out-compete resulting in the population shown in Condition Y. However, as host cells change to the activated state, the fungal population changes, resulting in Condition Z. (TIF $1067 \mathrm{~kb}$ )

Additional file 2: Derivation of equations used for modeling. (PDF $1657 \mathrm{~kb}$ )

Additional file 3: Figure S2. Colonization over time in Ca-educated mice and BALB/c nu/nu mice. For the mice whose colonization is depicted in Fig. 2a and b, the total CFU/gm fecal pellets was calculated. CFU/gm is shown for fecal pellets collected on Day 1, Day 2, and Day 6 post-inoculation with the mixture of 2 C. albicans strains. Each symbol shows the results from an individual mouse and the bar shows the geometric mean. Black triangle, BALB/c Ca-educated mice. Open diamond, BALB/c nu/nu mice. (TIF $244 \mathrm{~kb}$ )

Additional file 4: Figure S3. Parameter analysis. Panel A: Distribution of fungal payoffs. In a host playing the activated strategy, a, the efg 1 null strain typically had the lowest payoff. In a host playing the basal strategy, $b$, the ACT1pr-EFG1 strain received the lowest payoff. The payoff to WT cells in the nairve or immunodeficient host was most variable. Panel B: Correlation analysis of fungal payoffs. Values for fungal payoff were highly correlated when fungi were playing against a fixed host strategy. Fungal payoffs in one host environment did not correlate with payoffs in another host environment. (TIF $433 \mathrm{~kb}$ )

Additional file 5: Figure S4. Simulation of experimental data when values for $\varepsilon$ were changed. To determine how much values for $\varepsilon$ influenced colonization dynamics, the value of $\varepsilon$ in all hosts was set to either 0 (Panel A) or to the value estimated for $\mathrm{n}-\mathrm{BALB} / \mathrm{c}$ mice (Panel B). The model was then used to simulate $C$. albicans colonization dynamics. Orange, BALB/C nu/nu mice; blue, n-BALB/c mice; green, Ca-educated mice. When $\varepsilon$ was set to zero, model simulations predicted the $\Delta$ efg 1 null mutant strain to be completely outcompeted by WT cells in $n-B A L B / C$ mice within 6 days post inoculation. When $\varepsilon$ was set to the value observed in $\mathrm{n}-\mathrm{BALB} / \mathrm{C}$ mice, the resulting model simulations predicted that the $\Delta$ efg 1 null mutant strain would persist in Ca-educated mice. Thus, when the value of $\varepsilon$ was changed, a poor fit of the model to the data was observed. (TIF $112 \mathrm{~kb}$ )

Additional file 6: Figure S5. Correlation between transcript levels of EFG1 and other genes of interest. Normalized expression levels for genes shown in Fig. 4 are plotted as a function of EFG1 expression (shown on the $x$-axis in all panels). Each symbol indicates expression in C. albicans cells from an individual mouse. Expression of several genes correlated well with the expression of EFG1. (TIF $511 \mathrm{~kb}$ )

Additional file 7: Table S1. C. albicans strains used in this study. (PDF $54 \mathrm{~kb}$ )

Additional file 8: Table S2. Primers used in this study. (PDF $50 \mathrm{~kb}$ )

\section{Competing interests}

The authors declare no competing interests.

\section{Authors' contribution}

KMT and CAK designed the study and drafted the manuscript. EK participated in the design of the study. CAK coordinated the study. KMT constructed the mathematical model and performed the simulations. SEH, JVP, and CAK collected the experimental data. KMT, SEH, JAH, JVP, EK, and CAK analyzed the data and model. All authors critically revised the manuscript, contributed to the exposition of the results, and approved the final manuscript.

\section{Acknowledgements}

We thank Drs. Tim van Opijnen, Bree Aldridge, Kearney Gunsalus and Talya Davis for helpful discussion and Dr. Al Brown for catalyzing our collaboration. This research was supported by grants R01Al081794 and R01Al081794-02S1 from the National Institutes of Health to C.A.K. and by the European Commission through the European Marie Curie Initial Training Network, FINSysB (PITN-GA-2008-214004) to E.K. J.V.P. was partially supported by T32AI07422 and S.E.H. by T32GM008448 from the NIH. K.M.T. was supported by the European Commission through the European Marie Curie Initial Training Network, FINSysB (PITN-GA-2008-214004).

\section{Author details}

${ }^{1}$ Theoretische Biophysik, Humboldt-Universität zu Berlin, Invalidenstraße 42, D-10115 Berlin, Germany. ${ }^{2}$ Graduate Program in Molecular Microbiology, Sackler School of Graduate Biomedical Sciences and Department of Molecular Biology and Microbiology, Tufts University, Boston, MA 02111, USA. ${ }^{3}$ Department of Molecular Biology and Microbiology, Tufts University, 136 Harrison Ave., Boston, MA 02111, USA. ${ }^{4}$ Present address: Department of Biochemistry, University of Utah, Salt Lake City, UT 84112, USA. ${ }^{5}$ Genetics and Biochemistry Branch, National Institute of Diabetes and Digestive and Kidney Diseases, National Institutes of Health, Bethesda, MD 20892, USA.

Received: 22 December 2015 Accepted: 12 February 2016 Published online: 01 March 2016

\section{References}

1. Odds FC. Candida infections: an overview. Crit Rev Microbiol. 1987;15:1-5.

2. Nucci M, Anaissie E. Revisiting the source of candidemia: skin or gut? Clin Infect Dis. 2001;33:1959-67.

3. Miranda LN, van der Heijden IM, Costa SF, Sousa AP, Sienra RA, Gobara S, et al. Candida colonisation as a source for candidaemia. J Hosp Infect. 2009;72: 9-16.

4. Cole GT, Lynn KT, Seshan KR, Pope LM. Gastrointestinal and systemic candidosis in immunocompromised mice. J Med Vet Mycol. 1989;27:363-80.

5. Ekenna O, Sherertz RJ. Factors affecting colonization and dissemination of Candida albicans from the gastrointestinal tract of mice. Infect Immun. 1987; 55:1558-63.

6. Mellado E, Cuenca-Estrella M, Regadera J, Gonzalez M, Diaz-Guerra TM, Rodriguez-Tudela JL. Sustained gastrointestinal colonization and systemic dissemination by Candida albicans, Candida tropicalis and Candida parapsilosis in adult mice. Diagn Microbiol Infect Dis. 2000;38:21-8.

7. Koh AY, Kohler JR, Coggshall KT, Van Rooijen N, Pier GB. Mucosal damage and neutropenia are required for Candida albicans dissemination. PLoS Pathog. 2008;4:e35. 
8. Zelante T, De Luca A, Bonifazi P, Montagnoli C, Bozza S, Moretti S, et al. IL-23 and the Th17 pathway promote inflammation and impair antifungal immune resistance. Eur J Immunol. 2007;37:2695-706.

9. De Luca A, Montagnoli C, Zelante T, Bonifazi P, Bozza S, Moretti S, et al. Functional yet balanced reactivity to Candida albicans requires TRIF, MyD88, and IDO-dependent inhibition of Rorc. J Immunol. 2007;179:5999-6008.

10. Del Sero G, Mencacci A, Cenci E, d'Ostiani CF, Montagnoli C, Bacci A, et al. Antifungal type 1 responses are upregulated in IL-10-deficient mice. Microbes Infect. 1999;1:1169-80.

11. Mencacci A, Del Sero G, Cenci E, d'Ostiani CF, Bacci A, Montagnoli C, et al. Endogenous interleukin 4 is required for development of protective CD4+ T helper type 1 cell responses to Candida albicans. J Exp Med. 1998;187:307-17.

12. Mencacci A, Cenci E, Del Sero G, Fe d'Ostiani C, Mosci P, Trinchieri G, et al. $\mathrm{IL}-10$ is required for development of protective Th1 responses in IL-12deficient mice upon Candida albicans infection. J Immunol. 1998;161:6228-37.

13. Cenci E, Mencacci A, Del Sero G, d'Ostiani CF, Mosci P, Bacci A, et al. IFN-gamma is required for IL-12 responsiveness in mice with Candida albicans infection. J Immunol. 1998;161:3543-50.

14. Westwater C, Balish E, Warner TF, Nicholas PJ, Paulling EE, Schofield DA. Susceptibility of gnotobiotic transgenic mice (Tgepsilon26) with combined deficiencies in natural killer cells and T cells to wild-type and hyphal signalling-defective mutants of Candida albicans. J Med Microbiol. 2007;56: 1138-44.

15. Balish E, Warner TF, Nicholas PJ, Paulling EE, Westwater C, Schofield DA. Susceptibility of germfree phagocyte oxidase- and nitric oxide synthase 2deficient mice, defective in the production of reactive metabolites of both oxygen and nitrogen, to mucosal and systemic candidiasis of endogenous origin. Infect Immun. 2005;73:1313-20.

16. Vazquez-Torres A, Jones-Carson J, Wagner RD, Warner T, Balish E. Early resistance of interleukin-10 knockout mice to acute systemic candidiasis. Infect Immun. 1999;67:670-4.

17. Balish E, Wagner RD, Vazquez-Torres A, Jones-Carson J, Pierson C, Warner T. Mucosal and systemic candidiasis in IL-8Rh-/- BALB/C mice. J Leukoc Biol. 1999:66:144-50

18. Balish E, Wagner RD, Vazquez-Torres A, Pierson C, Warner T. Candidiasis in interferon-gamma knockout (IFN-gamma-/-) mice. J Infect Dis. 1998;178: 478-87.

19. Wagner RD, Vazquez-Torres A, Jones-Carson J, Warner T, Balish E. B cell knockout mice are resistant to mucosal and systemic candidiasis of endogenous origin but susceptible to experimental systemic candidiasis. J Infect Dis. 1996;174:589-97.

20. Clark JD. Influence of antibiotics or certain intestinal bacteria on orally administered Candida albicans in germ-free and conventional mice. Infect Immun. 1971;4:731-7.

21. Helstrom PB, Balish E. Effect of oral tetracycline, the microbial flora, and the athymic state on gastrointestinal colonization and infection of BALB/C mice with Candida albicans. Infect Immun. 1979;23:764-74.

22. Samonis G, Anastassiadou H, Dassiou M, Tselentis Y, Bodey GP. Effects of broad-spectrum antibiotics on colonization of gastrointestinal tracts of mice by Candida albicans. Antimicrob Agents Chemother. 1994;38:602-3.

23. Wiesner SM, Jechorek RP, Garni RM, Bendel CM, Wells CL. Gastrointestinal colonization by Candida albicans mutant strains in antibiotic-treated mice. Clin Diagn Lab Immunol. 2001:8:192-5.

24. Bendel CM, Kinneberg KM, Jechorek RP, Erlandsen SL, Sahar DE, Wells CL. The Candida albicans INT1 gene facilitates cecal colonization in endotoxintreated mice. Shock. 2000;13:453-8.

25. Kinneberg KM, Bendel CM, Jechorek RP, Cebelinski EA, Gale CA, Berman JG, et al. Effect of INT1 gene on Candida albicans murine intestinal colonization. J Surg Res. 1999;87:245-51.

26. Pierce JV, Kumamoto CA. Variation in Candida albicans EFG1 expression enables host-dependent changes in colonizing fungal populations. MBio. 2012;3:e00117-00112.

27. Rosenbach A, Dignard D, Pierce JV, Whiteway M, Kumamoto CA. Adaptations of Candida albicans for growth in the mammalian intestinal tract. Eukaryot Cell. 2010;9:1075-86.

28. White SJ, Rosenbach A, Lephart P, Nguyen D, Benjamin A, Tzipori S, et al. Self-regulation of Candida albicans population size during GI colonization. PLoS Pathog. 2007;3:e184.

29. Chen C, Pande K, French SD, Tuch BB, Noble SM. An iron homeostasis regulatory circuit with reciprocal roles in Candida albicans commensalism and pathogenesis. Cell Host Microbe. 2011;10:118-35.
30. Pierce JV, Dignard D, Whiteway M, Kumamoto CA. Normal adaptation of Candida albicans to the murine $\mathrm{Gl}$ tract requires Efg1p-dependent regulation of metabolic and host defense genes. Eukaryot Cell. 2012;12(1): 37-49

31. Lo HJ, Kohler JR, DiDomenico B, Loebenberg D, Cacciapuoti A, Fink GR. Nonfilamentous C. albicans mutants are avirulent. Cell. 1997:90:939-49.

32. Lorenz MC, Bender JA, Fink GR. Transcriptional response of Candida albicans upon internalization by macrophages. Eukaryot Cell. 2004;3:1076-87.

33. Stoldt VR, Sonnenborn A, Leuker CE, Ernst JF. Efg1p, an essential regulator of morphogenesis of the human pathogen Candida albicans is a member of a conserved class of bHLH proteins regulating morphogenetic processes in fungi. EMBO J. 1997;16:1982-91.

34. Doedt T, Krishnamurthy S, Bockmuhl DP, Tebarth B, Stempel C, Russell CL, et al. APSES proteins regulate morphogenesis and metabolism in Candida albicans. Mol Biol Cell. 2004:15:3167-80.

35. Ramage G, VandeWalle K, Lopez-Ribot JL, Wickes BL. The filamentation pathway controlled by the Efg1 regulator protein is required for normal biofilm formation and development in Candida albicans. FEMS Microbiol Lett. 2002;214:95-100.

36. Nantel A, Dignard D, Bachewich C, Harcus D, Marcil A, Bouin AP, et al. Transcription profiling of Candida albicans cells undergoing the yeast-tohyphal transition. Mol Biol Cell. 2002;13:3452-65.

37. Setiadi ER, Doedt T, Cottier F, Noffz C, Ernst JF. Transcriptional response of Candida albicans to hypoxia: linkage of oxygen sensing and Efg $1 \mathrm{p}$-regulatory networks. J Mol Biol. 2006;361:399-411.

38. Thewes S, Kretschmar M, Park H, Schaller M, Filler SG, Hube B. In vivo and ex vivo comparative transcriptional profiling of invasive and non-invasive Candida albicans isolates identifies genes associated with tissue invasion. Mol Microbiol. 2007;63:1606-28.

39. Walker LA, Maccallum DM, Bertram G, Gow NA, Odds FC, Brown AJ. Genome-wide analysis of Candida albicans gene expression patterns during infection of the mammalian kidney. Fungal Genet Biol. 2009;46:210-9.

40. Hameed S, Prasad T, Banerjee D, Chandra A, Mukhopadhyay CK, Goswami SK, et al. Iron deprivation induces EFG1-mediated hyphal development in Candida albicans without affecting biofilm formation. FEMS Yeast Res. 2008; 8:744-55.

41. Hummert S, Hummert C, Schroter A, Hube B, Schuster S. Game theoretical modelling of survival strategies of Candida albicans inside macrophages. J Theor Biol. 2010;264:312-8.

42. Webb JN. Game Theory: Decisions, Interaction and Evolution. Springer: Springer-Verlag London; 2007.

43. Cenci E, Mencacci A, Spaccapelo R, Tonnetti L, Mosci P, Enssle KH, et al. T helper cell type 1 (Th1)- and Th2-like responses are present in mice with gastric candidiasis but protective immunity is associated with Th1 development. J Infect Dis. 1995;171:1279-88.

44. Balish E, Balish MJ, Salkowski CA, Lee KW, Bartizal KF. Colonization of congenitally athymic, gnotobiotic mice by Candida albicans. Appl Environ Microbiol. 1984;47:647-52

45. Domer JE. Intragastric colonization of infant mice with Candida albicans induces systemic immunity demonstrable upon challenge as adults. J Infect Dis. 1988;157:950-8.

46. Cantorna MT, Balish E. Acquired immunity to systemic candidiasis in immunodeficient mice. J Infect Dis. 1991;164:936-43.

47. Bistoni F, Cenci E, Mencacci A, Schiaffella E, Mosci P, Puccetti P, et al. Mucosal and systemic T helper cell function after intragastric colonization of adult mice with Candida albicans. J Infect Dis. 1993;168:1449-57.

48. Cenci E, Mencacci A, Del Sero G, Fe d'Ostiani C, Montagnoli C, Bacci A, et al. Induction of protective Th1 responses to Candida albicans by antifungal therapy alone or in combination with an interleukin-4 antagonist. J Chemother. 1998;10:160-3.

49. Mencacci A, Cenci E, Del Sero G, Fe d'Ostiani C, Mosci P, Montagnoli C, et al. Defective co-stimulation and impaired Th1 development in tumor necrosis factor/lymphotoxin-alpha double-deficient mice infected with Candida albicans. Int Immunol. 1998;10:37-48.

50. Cutler JE, Corti M, Lambert P, Ferris M, Xin H. Horizontal transmission of Candida albicans and evidence of a vaccine response in mice colonized with the fungus. PLoS One. 2011;6:e22030.

51. Zelante T, lannitti RG, Cunha C, De Luca A, Giovannini G, Pieraccini G, et al. Tryptophan catabolites from microbiota engage aryl hydrocarbon receptor and balance mucosal reactivity via interleukin-22. Immunity. 2013;39:372-85. 
52. Carvalho A, Giovannini G, De Luca A, D'Angelo C, Casagrande A, lannitti RG, et al. Dectin-1 isoforms contribute to distinct Th1/Th17 cell activation in mucosal candidiasis. Cell Mol Immunol. 2012;9:276-86.

53. De Luca A, Zelante T, D'Angelo C, Zagarella S, Fallarino F, Spreca A, et al. IL-22 defines a novel immune pathway of antifungal resistance. Mucosal Immunol. 2010;3:361-73.

54. Hoops S, Sahle S, Gauges R, Lee C, Pahle J, Simus N, et al. COPASI-a COmplex PAthway SImulator. Bioinformatics. 2006;22:3067-74.

55. Sudbery PE. Growth of Candida albicans hyphae. Nat Rev Microbiol. 2011;9:737-48.

56. Biswas S, Van Dijck P, Datta A. Environmental sensing and signal transduction pathways regulating morphopathogenic determinants of Candida albicans. Microbiol Mol Biol Rev. 2007;71:348-76.

57. Cao F, Lane S, Raniga PP, Lu Y, Zhou Z, Ramon K, et al. The Flo8 transcription factor is essential for hyphal development and virulence in Candida albicans. Mol Biol Cell. 2006;17:295-307.

58. Tebarth B, Doedt T, Krishnamurthy S, Weide M, Monterola F, Dominguez A et al. Adaptation of the Efg1p morphogenetic pathway in Candida albicans by negative autoregulation and PKA-dependent repression of the EFG1 gene. J Mol Biol. 2003;329:949-62.

59. Srikantha T, Tsai L, Daniels K, Klar AJ, Soll DR. The histone deacetylase genes HDA1 and RPD3 play distinct roles in regulation of high-frequency phenotypic switching in Candida albicans. J Bacteriol. 2001;183:4614-25.

60. Hnisz D, Bardet AF, Nobile CJ, Petryshyn A, Glaser W, Schock U, et al. A histone deacetylase adjusts transcription kinetics at coding sequences during Candida albicans morphogenesis. PLoS Genet. 2012;8:e1003118.

61. Verdin $\mathrm{E}, \mathrm{Ott} \mathrm{M} .50$ years of protein acetylation: from gene regulation to epigenetics, metabolism and beyond. Nat Rev Mol Cell Biol. 2015;16(4):258-64

62. Lu Y, Su C, Mao X, Raniga PP, Liu H, Chen J. Efg1-mediated recruitment of NuA4 to promoters is required for hypha-specific Swi/Snf binding and activation in Candida albicans. Mol Biol Cell. 2008;19:4260-72.

63. Wang $X$, Chang P, Ding J, Chen J. Distinct and redundant roles of the two MYST histone acetyltransferases Esa1 and Sas2 in cell growth and morphogenesis of Candida albicans. Eukaryot Cell. 2013;12:438-49.

64. Russell C, Lay KM. Natural history of Candida species and yeasts in the oral cavities of infants. Arch Oral Biol. 1973;18:957-62.

65. Kim AS, Garni RM, Henry-Stanley MJ, Bendel CM, Erlandsen SL, Wells CL. Hypoxia and extraintestinal dissemination of Candida albicans yeast forms. Shock. 2003;19:257-62.

66. Zucchi PC, Davis TR, Kumamoto CA. A Candida albicans cell wall-linked protein promotes invasive filamentation into semi-solid medium. Mol Microbiol. 2010;76:733-48.

67. Sherman F. Getting started with yeast. Methods Enzymol. 1991;194:3-21.

68. Overbergh L, Giulietti A, Valckx D, Decallonne R, Bouillon R, Mathieu C. The use of real-time reverse transcriptase PCR for the quantification of cytokine gene expression. J Biomol Tech. 2003;14:33-43.

69. Chellan B, Yan L, Sontag TJ, Reardon CA, Hofmann Bowman MA. IL-22 is induced by $\mathrm{S100/calgranulin} \mathrm{and} \mathrm{impairs} \mathrm{cholesterol} \mathrm{efflux} \mathrm{in} \mathrm{macrophages}$ by downregulating ABCG1. J Lipid Res. 2014;55:443-54.

70. Hu L, Dixit VD, de Mello-Coelho V, Taub DD. Age-associated alterations in CXCL1 chemokine expression by murine B cells. BMC Immunol. 2004;5:15.

\section{Submit your next manuscript to BioMed Central and we will help you at every step:}

- We accept pre-submission inquiries

- Our selector tool helps you to find the most relevant journal

- We provide round the clock customer support

- Convenient online submission

- Thorough peer review

- Inclusion in PubMed and all major indexing services

- Maximum visibility for your research

Submit your manuscript at www.biomedcentral.com/submit
Biomed Central 